Research Article

\title{
A study on selected behavioral factors of mothers influencing acute diarrhoea in under- five children in a rural part of Kerala, India
}

\author{
Divya S. ${ }^{1}{ }^{*}$, C. R. Saju ${ }^{1}$, C. J. Navya ${ }^{1}$, Vidhu M. Joshy ${ }^{1}$, Jini M. P. ${ }^{1}, \operatorname{Radhamani}_{\text {M. V. }}{ }^{2}$
}

${ }^{1}$ Department of Community Medicine, Amala Institute of Medical Sciences, Thrissur, Kerala, India

${ }^{2}$ Department of Obstetrics and Gynaecology, Government Medical College, Kottayam, Kerala, India

Received: 13 June 2016

Accepted: 02 July 2016

\section{*Correspondence:}

Dr. Divya S.,

E-mail: divyaspdr89@gmail.com

Copyright: (C) the author(s), publisher and licensee Medip Academy. This is an open-access article distributed under the terms of the Creative Commons Attribution Non-Commercial License, which permits unrestricted non-commercial use, distribution, and reproduction in any medium, provided the original work is properly cited.

\begin{abstract}
Background: Diarrhoea remains an important cause of morbidity and mortality among underfive children. Globally it accounts for 2 million deaths per year. Diarrhoea is the third most common cause of death in underfive children, responsible for $13 \%$ deaths in India each year. Behaviour can also depend upon the socioeconomic status. Socioeconomic factors affect environmental, behavioral and nutritional risk factors. Proper nutrition, especially exclusive breast feeding is one of the most important interventions for its control .Inadequate personal hygiene along with other environmental factors are responsible for $90 \%$ of diarrhea. The objective is to assess behavioral factors of mothers influencing diarrhoea in underfive children.

Methods: Community- based cross- sectional study was conducted in a rural area among 103 mothers of underfive children with acute diarrhoea in the past six months.

Results: Most mothers were in the higher income 80 (77.6\%) group. Those who practised handwashing after toilet and before cooking was 96 (93.2\%). Proportion of mothers using boiled water for drinking was 99( 96.1\%); bottle feeding 77(74.8\%); and practised sanitary waste disposal methods 93(90.3\%). The practice of using boiled water was statistically significant among higher income group $(\mathrm{P}=0.047)$. Occupation of the mother was significantly associated with the habit of child's eatingout $(\mathrm{P}=0.019)$.

Conclusions: This study shows that the practice of handwashing and use of boiled water for drinking was lower among lower socioeconomic families. This warrants need to create awareness about it among low socioeconomic families in rural areas.
\end{abstract}

Keywords: Behavioral practices, Childhood diarrhoea, Hand washing, Mothers

\section{INTRODUCTION}

Globally, diarrhea accounts for 2 million deaths per year. Health is affected by environmental conditions and economic status. The public health importance of some practices like hand washing and food hygiene are important in reduction of diarrhea. Socio- economic factors may directly or indirectly affect environmental, behavioral and nutritional risk factors. The prevalence of hand washing practice in Kerala was found to be $35 \%{ }^{1}$ Low socio- economic status, scarcity of potable water, behavioural factors such as unhygienic practices, inadequate sanitation, faulty feeding practices, all may cause diarrhoea in children. ${ }^{2,3}$

According to WHO 2012 data, diarrhoeal disease alone amounts to an estimated $3.6 \%$ of the total DALY global burden of disease and is responsible for the deaths of 1.5 million people every year. It is estimated that $58 \%$ of that burden, or 842000 deaths per year, is attributable to unsafe water supply, sanitation and hygiene and includes 
361000 deaths of children under age five, mostly in developing countries according to WHO 2014 data.

Worldwide, the second leading cause of death in underfive children is diarrhoea. It is responsible for 2 million mortality and very high morbidity of under-five children every year. India has made steady progress in reducing deaths in children younger than 5 years, with total deaths declining from 2.5 million in 2001 to 1.5 million in $2012 .^{4}$

Diarrhea is the third most common cause of death in under-five children, responsible for $13 \%$ deaths in this age-group, killing an estimated 300,000 children in India each year. This remarkable reduction was possible due to the inception and success of many universal programs like expanded program on immunization, program for the control of diarrheal diseases and acute respiratory infection. $^{5}$

Even though the deaths among children under-5 years have declined, the proportional mortality accounted by diarrheal diseases still remains high. Diarrhea is the third most common cause of death in under-five children, responsible for $13 \%$ deaths in this age-group, killing an estimated 300,000 children in India each year.

Poor sanitation, unsafe water supply and certain behavioral factors such as inadequate personal hygiene of the care-giver are responsible for $90 \%$ of diarrhea. ${ }^{6}$

These can be easily improved by Health Promotion and Education. Childhood mortality in general and IMR in particular- indicators of social development. Children are at greatest risk between the ages of 6- 11 months. As they are weaned, infants are exposed to unsafe food, water and unsanitary surroundings. They begin to lose the protective effects of their mother's immunity and the immunological benefits of breast milk. Proper nutrition, especially exclusive breast feeding in the first six months and then continued breast feeding through at least age two, is one of the most important interventions for the control of diarrhoeal disease. Mothers have an important role. Mother's literacy, family income, feeding practices and environmental conditions are important determinants. Risk of malnutrition adds to it. Behavioural Change Communication strategies can contribute in significant ways for the prevention of diarrhoea in children. The present study is undertaken to study the behavioural factors among the mothers influencing occurrence of diarrhoea in under- five children.

NFHS-3 furnished data on morbidity due to diarrhoea among children of five years of age. It is important to study the linkage between water quality, household practices and diarrhoea morbidity among under-five $5 .{ }^{7}$

A study in gonda- the factors that potentially determine the occurrence of diarrhoea in children include malnutrition, poor personal hygiene, environmental problems, water availability and quality, unhygienic feeding practices, improper use of latrines, early discontinuation of breast feeding, child's age, maternal education and household income.

A study done by K. R. Thankappan done in Vembayam village of Thiruvananthapuram, on diarrhoea morbidity among under- five children, the prevalence of not practicing handwashing among mothers before feeding their child was significantly associated with diarrhea among the under-five children, ( $\mathrm{P}$ value is $0.004{ }^{8}$ Rey et. al. in his studies in Kolkata had also observed poor hand washing practices at community setting where the people considered other activities such as boiling and purification of water and cleanliness could have prevented diarrhea more efficiently than hand-washing alone. ${ }^{9}$

A multilevel study done on Socio- economic determinants of childhood diarrhoea in Sub Saharan Africa revealed that regardless of where individual care giver resides, treatment choices would be similar based on their level of Educational attainments. ${ }^{10}$

\section{METHODS}

A community- based cross-sectional study was conducted to assess the behavioural factors of the mothers influencing diarrhoea among under- five children in the past 6 months in a rural area of Thrissur district (Thrikkur panchayath). The study was conducted over a period of six months from January - June 2015, among the mothers of children under-five years with history of acute diarrhoea in the past six months.

The mothers of those children with transitional diarrhoea, organic pathology and allergy were excluded. The prevalence of practicing boiling water for drinking in rural area is $49.3 \% .^{11}$ The sample size calculated to be 103. By convenient sampling, one ward was chosen from the 17 wards of Thrikkur panchayat.

A street was randomly selected and house to house visit was done and the first mother of the under-five child in that street was selected. Consecutive houses with underfive children were surveyed till 103 mothers were obtained. The mothers were personally interviewed using a pre- tested structured questionnaire.

\section{Variables under study}

Socio- economic status: Family size, educational status and occupation. SES is assessed using modified prasad classification for per capita monthly income.

Behavioural factors: Hand washing practice, maintenance of food hygiene, bottle feeding, using boiled water for drinking and vaccination. 
The data obtained was coded and entered in microsoft Excel sheet and analysed using the statistical software Statistical Package for Social Sciences (SSPS Version16).

\section{RESULTS}

Most of the mothers belonged to the age group 26- 30 years $(44.7 \%)$. No mother belonged to age below 20 . About $35.9 \%$ of the mothers were either graduates or postgraduates and similar proportion of the mothers who attained high school education. Majority (77.6\%) were in the class 1 status of modified B.G. Prasad SES classification.

Table 1: Socio- demographic details of the study population.

\begin{tabular}{|lll|}
\hline $\begin{array}{l}\text { Age } \\
\text { category } \\
\text { (years) }\end{array}$ & Frequency $\mathbf{n = 1 0 3}$ & Percentage(\%) \\
\hline$<20$ & 0 & 0 \\
\hline $21-25$ & 43 & 41.7 \\
\hline $26-30$ & 46 & 44.7 \\
\hline $31-35$ & 12 & 11.7 \\
\hline$>36$ & 2 & 1.9 \\
\hline
\end{tabular}

Table 2: Socio- economic details of the study population.

\begin{tabular}{|lll|}
\hline $\begin{array}{l}\text { Educational } \\
\text { status }\end{array}$ & $\begin{array}{l}\text { Number } \\
(\mathbf{n = 1 0 3 )}\end{array}$ & Percentage(\%) \\
\hline Primary school & 12 & 11.7 \\
\hline Middle school & 7 & 6.8 \\
\hline High school & 37 & 35.9 \\
\hline Diploma & 8 & 7.8 \\
\hline $\begin{array}{l}\text { Graduate/Post } \\
\text { graduate }\end{array}$ & 37 & 35.9 \\
\hline Professional & 2 & 1.9 \\
\hline
\end{tabular}

Table 3: Socio demographic characteristics of children.

\begin{tabular}{|lll|}
\hline $\begin{array}{l}\text { Characteristics } \\
\text { Age of the child }\end{array}$ & Frequency & Percentage $(\%)$ \\
\hline$<6$ months & 0 & 0 \\
\hline 6 m- $<2$ years & 26 & 25.2 \\
\hline$\geq 2-5$ years & 77 & 74.8 \\
\hline Gender of the child & & \\
\hline Females & 58 & 56.3 \\
\hline Males & 45 & 43.7 \\
\hline
\end{tabular}

The mother's behavioural practices were found to be better here. Hand washing with soap and water was $93.2 \%$. The practice of boiling water for drinking was 96.1\%. Exclusive breast feeding upto 6 months $86.4 \%$. Proper washing of vegetables and utensils Vaccination coverage was $95.8 \%$ which is very much higher compared to the national average.

About the sociodemographic characteristics of the children, $74.8 \%$ belonged to the age group of $2-5$ years.and no child was below six months. Majority of the children $(56.3 \%)$ were females.

Table 4: Mother's behavioural practices.

\begin{tabular}{|c|c|c|c|}
\hline \multicolumn{2}{|c|}{ Characteristics } & Frequency & Percentage \\
\hline \multirow{2}{*}{$\begin{array}{l}\text { Hand } \\
\text { washing } \\
\text { with } \\
\text { soap and } \\
\text { water }\end{array}$} & After toilet & 7 & 6.8 \\
\hline & $\begin{array}{l}\text { Both after toilet } \\
\text { and before } \\
\text { feeding }\end{array}$ & 96 & 93.2 \\
\hline \multicolumn{2}{|c|}{$\begin{array}{l}\text { Boiling water before } \\
\text { drinking }\end{array}$} & 99 & 96.1 \\
\hline \multirow{3}{*}{$\begin{array}{l}\text { Feeding } \\
\text { practices }\end{array}$} & $\begin{array}{l}\text { Exclusive } \\
\text { Breast Feeding } \\
\text { upto } 6 \text { months }\end{array}$ & 89 & 86.4 \\
\hline & $\begin{array}{l}\text { Proper washing } \\
\text { of vegetables } \\
\text { and utensils }\end{array}$ & 99 & 96.1 \\
\hline & Bottle feeding & 77 & 74.8 \\
\hline \multicolumn{2}{|c|}{$\begin{array}{l}\text { Vaccination } \\
\text { Vit A and Measles given }\end{array}$} & 98 & 95.1 \\
\hline
\end{tabular}

Table 5: Socio- economic status according to Modified B.G. Prasad classification.

\begin{tabular}{|lll|}
\hline Category & $\begin{array}{l}\text { Frequency } \\
\mathbf{n = 1 0 3}\end{array}$ & $\begin{array}{l}\text { Percentage } \\
(\boldsymbol{\%})\end{array}$ \\
\hline Class1( $\geq 4372)$ & 80 & 77.6 \\
\hline Class 2(2186- 4371) & 15 & 14.6 \\
\hline Class 3(1311- 2185) & 2 & 1.9 \\
\hline Class 4(656- 1310$)$ & 2 & 1.9 \\
\hline Class 5(<656) & 4 & 3.8 \\
\hline
\end{tabular}

\section{DISCUSSION}

Young age, low socioeconomic status, poor maternal literacy, presence of under-five sibling in the family, birth weight, inadequate breastfeeding, malnutrition, poor sanitation and hygiene practices of the mother are associated with a higher incidence of diarrheal diseases in young children. ${ }^{12}$

Measures for prevention of diarrheal diseases include the use of safe water, hand-washing, food safety, safe disposal of excreta, promoting exclusive breastfeeding and immunization against measles. Vitamin $\mathrm{A}$ supplementation does not reduce the incidence of diarrhea or diarrhea- related mortality in neonates and children $<6$ months, but there is a benefit in children aged 6-59 months. ${ }^{13}$ Children belonging to poor socioeconomic status had a higher diarrheal incidence than the better socioeconomic group. ${ }^{14}$ Educational status of the mother showed a positive correlation with the 
incidence of diarrheal diseases among children in India. ${ }^{15}$ Studies have shown that families with more than one child had an attack rate for diarrheal diseases that was 22$70 \%$ higher than in houses with just one child $<5$ year old.Poor sanitation and unhygienic conditions are important risk factors for diarrhea. ${ }^{16}$ Inclusion of Rotavirus vaccination of infants into national immunization programs has been recommended in areas where under- five mortality due to diarrheal diseases is $>10 \% .^{17}$

Lack of toilets remains one of the leading causes of illness and death among children. According to United Nations Children's Fund report (UNICEF), 626 million people in India practice open defecation. Poor sanitation, lack of access to clean water, and inadequate personal hygiene are responsible for an estimated $88 \%$ of childhood diarrhea in India. $^{18}$

Though the sanitation coverage in India is $59 \%$,there is a huge disparity in terms of use of toilets in the rural-urban areas (34\% and $80 \%$, respectively). However, there have been significant improvements in households using toilets in rural areas during the last 10 years. India has reached the Millenium Development Goal (MDG) 7 target on improved drinking water sources with $86 \%$ coverage, however, the piped water as a drinking water source has remained as $24 \%$. $^{19}$

Hand-washing before preparing food is a particularly important opportunity to prevent childhood diarrhea and it works best when it is part of a package of behavior change interventions. Washing hands after defecating or handling children's feaces and before handling food entails an average of 32 hand washes a day and consumes 201 of water. ${ }^{20}$

Based on current evidence, washing hands with soap can reduce the risk of diarrheal diseases by $42-47 \% .^{21}$

A survey conducted by UNICEF in 2005 on well-being of children and women had shown that only $47 \%$ of rural children in the age-group 5-14 wash hands after defecation. $^{22}$

Another Study showed that the open disposal of waste around the house was an independent risk factor for diarrhea. The simple explanation might be that inappropriate disposal of waste provides breeding site for insects, which may carry diarrhea pathogens from the waste to water and food. ${ }^{23}$ and importance of hand washing in reducing the occurrence of childhood diarrhea. ${ }^{24}$ However, monitoring correct hand washing behavior at critical times is challenging.

Mode of water transportation, and poor handling of water at the household level, presence of wastewater in the street, refuse storage, collection and disposal, domestic water reservoir conditions, faeces disposal and presence of vectors predispose the under-five children to diarrhea. ${ }^{25}$ Indiscriminate stool disposal by the mothers, lack of hand- washing before feeding their children and hand-washing without soap were associated with increased risk. ${ }^{26}$

The prevalence of diarrhea varies according to education of mother being significantly lower among children of more educated mothers (secondary or higher) than among children of mothers with no or primary education. This is probably because more education provides the knowledge of the rules of hygiene, feeding and weaning practices, the interpretation of symptoms and enhances timely action to childhood illness. $^{27,28}$

A comparative study of urban areas of Ghana, Egypt, Brazil and Thailand by Timaeus and Lush clearly indicates that children's health is affected by environmental conditions and economic status of the household. According to these authors, children from better-off households have lower diarrhoeal morbidity and mortality in Egypt, Thailand, and Brazil. Such differentials in diarrhoeal diseases by household economic status is probably due to differences in child care practices, for instance preparation of weaning foods and personal hygiene. ${ }^{29}$

Another study observed a decrease in colony count following hand washing with soap in $60 \%$ of the samples in a study conducted in areas around Kolkata. The evidence suggested that hand washing with soap reduced the bacterial count in majority of the respondents. At the same time, an increase in colony count was seen in $30 \%$ samples that were either pond water users or food servers from a canteen using dirty clothes for drying hands after washing. Therefore, to have a real impact, particularly in reducing the incidence of diseases, three aspects of hand washing seem to be important: washing hands with soap and following all steps diligently, using clean water and drying hands with a clean cloth. ${ }^{30}$

The practice of hand washing after toilet and before cooking was $96(93.2 \%)$ in the present study. Observed rates of hand washing before handling food and after using the toilet $-34 \%$, according to fast facts and figures about hand washing, UNICEF. The results are consistent with that of other studies, $35 \%{ }^{21}, 44 \%$ in $2003^{31}$ and $47 \%$ in $2005^{32}$.

Practice of boiling water before drinking was very much higher. Prevalence of using boiled water was 99(96.1\%) in the present study. Hand washing should be practiced before cooking and after toilet. Comparing with other studies- Practice of boiling water in rural areas of Kerala $49.3 \%^{11}$

This study shows that the practice of handwashing and use of boiled water for drinking was low among lower socio-economic families compared to others. This warrants a need to create awareness about hand washing 
and use of boiled water for drinking among low socioeconomic families in rural areas.

Practice of hand washing after toilet and before cooking$93.2 \%$ in my study is very higher compared to other studies where it is $35 \%{ }^{1}$

Practice of boiling water- is higher here but needs improvement. History of child eating outside prior to diarrhoea is found to be higher here. Practice of exclusive breast feeding upto six months is very much better compared to other rural areas. The children who had taken Vitamin A and Measles (95.1\%) is also of better proportion.

\section{CONCLUSION}

Practice of boiling water- is higher here but needs improvement. Despite gains in controlling mortality related to diarrheal disease, the burden of the disease remains unacceptably high. Reviewing current scenario presents an unprecedented opportunity to save many more children. Focus on comprehensive diarrheal disease control strategy through improved case management, addressing social determinants of health like environmental sanitation and clean drinking water, health promotion regarding preventive practices like breastfeeding and research in the field of cost-effective interventions, is crucial to reduce the burden of diarrhea among children in India. This study shows that the practice of handwashing and use of boiled water for drinking was low among lower socioeconomic families compared to others. This warrants a need to create awareness about handwashing and use of boiled water for drinking among low socio- economic families in rural areas. A limitation of this study is that since it is based on self-reported information provided by the mothers, there may be some inaccurate reporting due to the recall bias, also mothers may say socially desirable answer.

\section{ACKNOWLEDGEMENTS}

The author would like to thank Dr.CR Saju, Professor and Head of the Department, for his guidance, excellence and inspiration through out the conduct of research . I would also thank Dr. Radhamani M.V. for her continuous inspiration and support.I also thank all the coauthors, faculty, friends and research centre for all the co-operation and guidance that had supported me.

\section{Funding: No funding sources}

Conflict of interest: None declared

Ethical approval: The study was approved by the Institutional Ethics Committee

\section{REFERENCES}

1. The Handwashing HandBook. A Guide for developing a hygiene promotive program to increase handwashing with soap.
2. Boschi-Pinto Velebt Estimating child mortality due to diarrhea in developing countries.

3. Black RE. Diarrhoeal disease and child morbidity and mortality. Population development review. 1984.

4. Bhan MK. Accelerated progress to reduce under-5 mortality in India. Lancet Glob Health. 2013;1:e172-3.

5. Bassani DG, Kumar R, Awasthi S, Morris SK, Paul VK, et al. Million Death Study Collaborators. Causes of neonatal and child mortality in India: A nationally representative mortality survey. Lancet. 2010;376:1853-60.

6. UNICEF. Sanitation issue. Addis Ababa: Ethiopian Newsletter; 2004.

7. NFHS-3.India 2005-2006.

8. Kutty VR, Thankappan KR, Kannan KP, Aravindan KP. How Socio-economic status affects health of Kerala state.

9. Ray. A pilot survey on handwashing among some communities of West Bengal. Indian Journal of Public Health. 2006;50:227-30.

10. Socio-economic determinants in selecting childhood diarrhoea treatment options in Sub-Saharan Africa: A multilevel model,Olatunde Aremu,Stephen Lawoko, Tahereh Moradi, and Koustuv Dalal Ital J Pediatr. 2011.

11. Health care scenario in Kerala by T.D. Simon.

12. Park K. Epidemiology of communicable disease. Textbook of Preventive and Social Medicine. $23^{\text {rd }}$ ed. Jabalpur, India: Banarsidas Bhanot; 2015.

13. Shah D, Choudhury P, Gupta P, Mathew JL, Gera T, Gogia S, et al. Promoting appropriate management of diarrhea: a systematic review of literature for advocacy and action: UNICEF-PHFI series on newborn and child health, India. Indian Pediatr. 2012;49:627-49.

14. Gupta P, Murali MV, Seth A. Epidemiology of diarrhea in urban slums. Indian Pediatr.1998;35:147-51.

15. Singh J, Gowriswari D, Chavan BR, Patiat RA, Debnath AC, Jain DC, et al. Diarrhoeal diseases amongst children under fi ve. A study in rural Alwar. J Commun Dis. 1992;24:150-5.

16. Reddaiah VP, Kapoor SK. Epidemiology of diarrhea and its implications for providing services. Indian $\mathbf{J}$ Pediatr. 1991;58:205-8.

17. Verma R, Khanna P, Chawla S. Rotavirus vaccine can save millions of children's lives in developing countries. Hum Vaccin Immunother. 2012;8:272-4.

18. The situation of children in India: a profi le. Available at: http:// www.unicef.org/india/health.html.

19. Graeff JA, Elder JP, Booth EM. Communication for Health and Behavior Change: a developing country perspective. San Francisco, CA: Jossey Bass; 1993.

20. Curtis V, Cairncross S. Effect of washing hands with soap on diarrhoea risk in the community: A systematic review. Lancet Infect Dis. 2003;3:27581. 
21. Huttly SRA, Morris SS, Pisani V. Preventing diarrhoea in young children in developing countries. Bulletin of the Wold Health Organization. 1997;75 (2):163-74.

22. The situation of children in India: a profile. Available at: http:// www.unicef.org/india/health.html.

23. Godana W, Mengiste B, Environmental Factors Associated With Acute Diarrhea among Children Under Five Years of Age in Derashe District, Southern Ethiopia, Science Journal of public Health. 2013;1(3).

24. International rescue committee, understanding hand washing behavior in Kenya, Thailand,

25. Simiyu S. Water risk factors pre-disposing the under fi ve children to diarrhoeal morbidity in Mandera district, Kenya. East Afr J Public Health. 2010;7:353-60.

26. Kumar SG, Subitha L. Diarrhoeal diseases in developing countries: A situational analysis. Kathmandu Univ Med J (KUMJ). 2012;10:838.hiopia 2011.

27. Kirkwood BR. Diarrhea, in Feachem and Jamison (eds) Disease and Mortality in Sub-Saharan Africa. Oxford University Press.1991.

28. Diame EH, Ndiaye S, Airey P. Diarrhoeal morbidity among young children: Findings from the DHS survey of Senegal 1986, in Hill Allen G. (ed) Determinants. 1990.

29. Timaeus IM, and Lush, L. (1995) Intra-urban differentials in child health. Health Transition Review 5. 1995:163-90.

30. Ray SK, Dobe M, Lahiri A, Basu SS. Hand washing practices in urban and rural communities in and around Kolkata, West Bengal. Indian J Public Health. 2009;53:1192-5.

31. Curtis V, Cairncross S. Effect of washing hands with soap on diarrhoea risk in the community: a systematic review. The Lancet infectious diseases. 2003;3:275-81.

32. Fewtrell L, Kaufmann RB, Kay D, Enanoria W, Haller L, Colford JM. Water, sanitation, and hygiene interventions to reduce diarrhoea in less developed countries: a systematic review and metaanalysis. The Lancet infectious diseases.2005;5:4252.

Cite this article as: Divya S, CR Saju, CJ Navya, Joshy VM, Jini MP, Radhamani MV. A study on selected behavioral factors of mothers influencing acute diarrhoea in under- five children in a rural part of Kerala, India. Int J Community Med Public Health 2016;3:2211-6. 